\title{
DETECÇÃO DE LISTERIA MONOCYTOGENES EM CORTES CÁRNEOS DE SUÍNOS ABATIDOS EM FRIGORÍFICO DA REGIÃO NOROESTE DO ESTADO DO PARANÁ
}

Vanessa Augusto Praça Julião ${ }^{1}$, Gilnéia da Rosa ${ }^{2}$, Luiz Sergio Merlini ${ }^{3}$, Jady Slaviero Tieppo $^{4}$, Adalgiza Pinto Neto ${ }^{5}$

${ }^{1}$ Mestre em Ciência Animal pelo Programa de Pós-Graduação em Ciência Animal com Ênfase em Produtos Bioativos da Universidade Paranaense (UNIPAR), Umuarama-PR, Brasil.

${ }^{2}$ Médica Veterinária, mestranda em Zootecnia Universidade do Estado de Santa Catarina, (UDESC), Chapecó-SC, Brasil. E-mail: gilneia.medvet@gmail.com 3Docente do Programa de Pós-graduação em Ciência Animal com Ênfase em Produtos Bioativos da Universidade Paranaense (UNIPAR), Umuarama-PR, Brasil. 4 Médica Veterinária Universidade Paranaense (UNIPAR), Umuarama-PR, Brasil.

5 Docente do curso de Medicina Veterinária, Universidade Federal da Fronteira Sul. Campus Realeza. Realeza-PR, Brasil.

\section{Recebido em: 06/04/2019 - Aprovado em: 10/06/2019 - Publicado em: 30/06/2019 DOI: 10.18677/EnciBio_2019A50}

\begin{abstract}
RESUMO
A Listeria monocytogenes é amplamente encontrada na natureza, normalmente em ambientes naturais, água, solo, excrementos humanos e de animais. Este microrganismo atualmente destaca-se entre os patógenos causadores de graves toxiinfecções alimentares, sendo uma das principais causas de morte em países subdesenvolvidos e em desenvolvimento, com taxa de letalidade podendo chegar até $70 \%$. A bactéria, responsável pela doença listeriose, é encontrada normalmente no trato intestinal dos suínos, facilitando desta forma a contaminação da carne e subprodutos durante 0 abate e processamento, bem como até o mercado consumidor quando não são cumpridas as Boas Práticas de Fabricação e demais processos de higienização pela indústria alimentícia. Desta forma, esta pesquisa teve como objetivo isolar e identificar a presença de Listeria monocytogenes em 320 amostras diferenciadas em oito tipos de cortes cárneos de suíno resfriados na desossa, sendo 40 amostras de pernil, paleta, lombo, copa-lombo, papada, mascara, barriga e costela, provenientes de um frigorífico localizado na região noroeste do estado do Paraná, sob Serviço de Inspeção Federal, durante o período de janeiro de 2015 a março de 2017. Como metodologia laboratorial foi utilizado o protocolo definido pela International Standard Organization, ISO 11290-1 e ISO 11290-2. Todas as amostras apresentaram ausência de L. monocytogenes, demonstrando condições higiênico sanitárias satisfatórias e evidenciando boas práticas de manipulação sendo cumpridas pelo frigorífico, não oferecendo risco de contaminação aos consumidores, no entanto, preconiza-se a continuidade da
\end{abstract}


aplicação de forma efetiva de tais práticas para que se mantenha este padrão microbiológico e qualidade do produto.

PALAVRAS-CHAVE: listeriose, saúde pública, suínos, toxiinfecções alimentares.

\title{
DETECTION OF LISTERIA MONOCYTOGENES IN CUTTINGS OF SWINE POWDERED IN REFRIGERATOR OF THE NORTHWEST REGION OF THE STATE OF PARANÁ
}

\begin{abstract}
Listeria monocytogenes is widely found in nature, usually in natural environments, water, soil, human and animal excreta. This micro-organism currently stands out among the pathogens causing serious foodborne diseases, being one of the main causes of death in underdeveloped and developing countries, with a lethality rate of up to $70 \%$. The bacterium, responsible for the disease listeriosis, is normally found in the intestinal tract of the pigs, thus facilitating the contamination of meat and byproducts during slaughter and processing, as well as to the consumer market when Good Manufacturing Practices and other processes are not complied with of hygiene by the food industry. The objective of the present study was to isolate and identify the presence of Listeria monocytogenes in 320 different samples in eight types of pork cuts in the bones, 40 samples of shank, shoulder, loin, jowl, mascara, belly and rib, from a refrigerator located in the northwest region of the state of Paraná, under Federal Inspection Service, from January 2015 to March 2017. As laboratory methodology was used the protocol defined by the International Standard Organization, ISO 112901 and ISO 11290 2. All samples showed absence of L. monocytogenes, demonstrating satisfactory sanitary hygienic conditions and evidencing good handling practices being fulfilled by the refrigerator, offering no risk of contamination to consumers, however, it is recommended the continuity of the effective application of such practices to to maintain this microbiological standard and product quality.
\end{abstract}

KEYWORDS: listeriosis, public health, swine, food toxins.

\section{INTRODUÇÃO}

A carne suína é considerada como uma importante fonte de proteína animal, com produção anual de aproximadamente 110 milhões de toneladas. A China é o país que mais produz suínos com cerca de 55 milhões de toneladas, seguido por União Europeia e Estados Unidos da América, sendo o Brasil o quarto maior produtor com três milhões de toneladas de carne suína (ABPA, 2014).

Com o aumento de produção e consumo de proteínas de origem animal, surgem conjuntamente riscos microbiológicos relacionados à segurança destes alimentos, como novos patógenos, resistência antimicrobiana e de ambiente, desafiando consideravelmente os sistemas e legislações atuais que prezam pela segurança alimentar (OMS, 2015). O aumento do consumo de carnes e seus derivados pelo ser humano deve-se a busca pela praticidade no preparo de alimentos e qualidade nutritiva, em alternância, a indústria alimentícia aprimora técnicas com a finalidade de garantir produtos microbiologicamente aptos para o consumo, afim de que os mesmos não representem riscos à saúde do consumidor com a ocorrência de toxiinfecções alimentares.

Entre os patógenos causadores de toxiinfecções alimentares, destaca-se a Listeria monocytogenes, microrganismo que se encontra 
amplamente distribuído na natureza, sendo o homem e várias espécies animais atuantes como reservatório para este patógeno (DA SILVA et al., 2011), que é responsável pela listeriose, doença grave, que pode ser transmitida pelo consumo de leite e queijos contaminados, vegetais crus não higienizados, carnes e seus subprodutos produzidos de forma inadequada e sem padrões de boas práticas de fabricação, podendo levar a óbito indivíduos imunodeprimidos, idosos, gestantes e crianças (SILVA et al., 2016).

Atualmente entre os principais alimentos envolvidos em surtos alimentares, a carne suína e seus derivados correspondem a $0,82 \%$ dos casos em que foi possível a identificação do alimento, podendo ser ainda maior, uma vez que na maioria dos casos ocorridos, o agente etiológico ou o tipo de alimento não é identificado, além de que doenças de origem alimentar não são de notificação obrigatória no Brasil, omitindo os reais dados epidemiológicos (BRASIL, 2018).

Amplamente encontrada em alimentos e no trato intestinal de suínos, a $L$. monocytogenes torna-se um dos principais microrganismos atualmente pesquisados para avaliação microbiológica de carne suína e de seus principais subprodutos. Em um frigorífico as carcaças podem ser contaminadas desde o processamento de abate dos animais, onde as fezes podem ser uma fonte de contaminação ou a partir de contaminações que podem estar presentes no ambiente produtivo, podendo ser encontrada em superfícies de utensílios e equipamentos (MEDEIROS et al., 2017). Ainda, Caselani et al. (2013) reforçam que o não cumprimento das medidas de prevenção e higienização do frigorífico, bem como acondicionamento dos produtos de forma incorreta na pós produção, elevam o risco de contaminação pelo patógeno e de transmissão aos consumidores, bem como a disseminação ambiental.

Desta forma, esta pesquisa teve como objetivo isolar e identificar a presença de Listeria monocytogenes em 320 amostras diferenciadas em oito tipos de cortes cárneos de suíno resfriados na desossa, provenientes de um frigorífico localizado na região noroeste do estado do Paraná, sob Serviço de Inspeção Federal, durante o período de janeiro de 2015 a março de 2017.

\section{MATERIAL E MÉTODOS}

Foram analisadas 320 amostras de oito tipos de cortes cárneos de suíno resfriados no momento da desossa, provenientes de um frigorífico localizado na região noroeste do estado do Paraná, sob Serviço de Inspeção Federal. Foram coletadas 250 gramas de cada corte, sendo 40 amostras de pernil, paleta, lombo, copa-lombo, papada, mascara, barriga e costela. Sendo acondicionadas individualmente em sacos de amostragem estéreis, os quais foram fechados assepticamente, identificados e armazenados em caixa isotérmica com gelo reciclável e transportadas ao laboratório da empresa para análise. Sendo o período de coleta realizado de janeiro de 2015 a março de 2017.

Para o isolamento e enumeração de $L$. monocytogenes foi utilizada a metodologia preconizada pelo International Standard Organization ISO 11290-1 e ISO 11290-2 (2004). Primeiramente as amostras foram submetidas ao enriquecimento seletivo, no qual alíquotas de 25 gramas de cada amostra foram homogeneizadas em $225 \mathrm{~mL}$ de caldo enriquecimento para Listeria (LEB) e após incubadas por 24 horas em estufa bacteriológica a $30^{\circ} \mathrm{C}$. Após foi realizado um segundo enriquecimento seletivo utilizando-se $0,1 \mathrm{~mL}$ do LEB incubado em $10 \mathrm{~mL}$ de Caldo Fraser e levado a estufa bacteriológica por $24-48$ horas a $35^{\circ} \mathrm{C}$. Após a incubação no Fraser, foi realizado o Plaqueamento seletivo para 
seleção e isolamento utilizando-se Ágar Oxford e levado a estufa bacteriológica por 24-48 horas a $35^{\circ} \mathrm{C}$. Após este processo, três a cinco colônias características foram selecionadas e estriadas em placa TSA - YE (Agar Extrato de Levedura Triptona de Soja) $0,6 \%$ de extrato de levedura, por $24-48$ horas em estufa a $35^{\circ} \mathrm{C}$. Da placa de TSA-YE foi transferido para tubo com TSA-YE e procedido aos testes para confirmação de L. monocytogenes: Catalase, Motilidade (em estufa a $25^{\circ} \mathrm{C}$ por 7 dias), Fermentação de açúcar: Ramnose, Manitol e Xilose (em estufa a $30^{\circ} \mathrm{C}$ por 36 horas) e Hemólise (em estufa a $35^{\circ} \mathrm{C}$ por $24-48$ horas) (IS0 2004).

\section{RESULTADOS E DISCUSSÃO}

Das 320 amostras de cortes cárneos de suíno analisadas, todas apresentaram ausência de $L$. monocytogenes em 25 gramas de produto, não oferecendo risco de contaminação aos consumidores e de intoxicações alimentares. Em relação à Legislação Brasileira, a Resolução $\mathrm{n}^{\circ}$ 12, de 02 de janeiro de 2001, do Ministério da Saúde, não determina limites ou padrões regulatórios para $L$. monocytogenes em produtos cárneos (ANVISA, 2001). Porém, o Ministério da

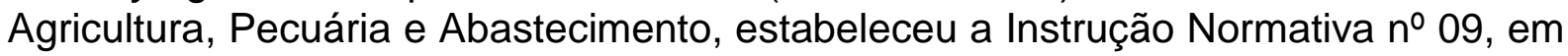
08 de abril de 2009, em que, estabelece procedimentos de controle para a $L$. monocytogenes em produtos de origem animal prontos para o consumo (BRASIL, 2009).

Com o crescimento da produção de suínos no Brasil, órgãos como Ministério da Agricultura, Pecuária e Abastecimento (MAPA) têm focado nos riscos à saúde pública, criando assim Programas de monitoria como o Programa Nacional de Controle de Patógenos (PNCP), monitorando principais patógenos como a Salmonella, Escherichia coli e L. monocytogenes de grande importância à saúde pública. Mesmo com resultado negativo para L. monocytogenes nesta pesquisa, ressalta-se a importância do cumprimento dos procedimentos de autocontrole e prevenção como Procedimentos Padrão de Higiene Operacional (PPHO), Análise de Perigos e Pontos Críticos de Controle (APPCC), Boas Práticas de Fabricação (BPF), bem como a higienização do ambiente de abatedouros-frigoríficos de forma eficiente e rigorosa para que não ocorra a contaminação de produtos e derivados com microrganismos patogênicos e consequentemente infecções alimentares (RODRIGUES et al., 2017).

Scallan et al. (2011), realizaram um estudo epidemiológico nos Estados Unidos da América com todas as doenças transmitidas por alimentos, durante o período de 2000-2008. Neste, constataram que a listeriose, doença causada pela $L$. monocytogenes, comprometeu a saúde de 1.455 pessoas e deste total 255 pacientes foram a óbito, todos os casos foram confirmados por teste laboratoriais, elevando a precisão dos diagnósticos. Ainda segundo estes autores, estima-se que patógenos de origem alimentar ocasionam 37, 2 milhões de doenças neste país e são responsáveis por óbito de 2.612 pessoas por ano, sendo a listeriose responsável por $19 \%$ destes casos.

No Brasil, Neves (2015), no período de 2007 a 2014, realizou um levantamento epidemiológico de surtos causados por intoxicações alimentares, verificando 49.231 casos notificados pelo Departamento de Informática do Sistema Único de Saúde (DATASUS), sendo maior a prevalência nas regiões sudeste e noroeste com 22.687 (45.9\%) e 16.215 (32.8\%) casos, respectivamente. No entanto, não foi mencionada a origem destes surtos e a ocorrência de óbitos, uma vez que no Brasil as Doenças Transmitidas por Alimentos não são de 
notificação obrigatória, dificultando o controle de tais enfermidades e investigações de empresas processadoras de alimentos que não cumprem a legislação referente a prevenção de DTAs, bem como a confirmação do diagnóstico e assim a conscientização da população.

Durante o período de 1978-2000, no estado do Paraná, foi realizado levantamento de dados epidemiológicos de DTAs. O número de surtos causados por origem bacteriana foi de 1.195 correspondendo $59,8 \%$ do total de casos relatados no período, também foram relacionados os agentes químicos e de outras causas que apresentaram $40,2 \%$ dos surtos registrados. O agente que obteve o maior número de surtos foi o Staphylococcus aureus com 41,2\%, em segundo lugar a Salmonela sp. com 33,8\% dos casos, já a Listeria monocytogenes foi descrita como outros, sendo um total de 15 (1,3\%) casos (AMSON et al., 2006). Analisando tais resultados evidencia-se a baixa casuística relacionada à listeriose, ocasionando em muitos casos a não investigação e confirmação já que muitas investigações microbiológicas são focadas nos agentes mais comuns ocasionadores de surtos alimentares.

Pissetti et al. (2012), avaliaram L. monocytogenes em fezes de suínos depositadas no piso das pocilgas de espera que alojava o lote de abate e superfície de carcaças na etapa do pré-resfriamento pertencentes ao mesmo lote das amostras das pocilgas, em três frigoríficos no estado de Santa Catarina. Das 18 amostras de fezes colhidas das pocilgas $66,7 \%$ foram positivos para $L$. innocua e somente uma amostra apresentou o gênero L. monocytogenes. $O$ total de amostras de carcaças coletadas no pré-resfriamento foram 252, sendo dividido em 84 amostras para cada frigorifico. O primeiro apresentou 1,2\% amostras positivas, já o segundo frigorifico obteve a maior contaminação $54,8 \%$ e o terceiro $3,6 \%$ amostras positivas para $L$. monocytogenes. De acordo com Casanova et al. (2014), pode ocorrer um alto índice de contaminação dos produtos e subprodutos, tornando estes dados preocupantes para a saúde dos consumidores de regiões com altos índices de isolamento deste microrganismo.

Diferentes trabalhos estão disponíveis descrevendo a caracterização de $L$. monocytogenes isolada de matadouros, carne suína e seus subprodutos por sorotipagem baseada em Reação de Cadeia de Polimerase - PCR (MELONI et al., 2013). De acordo com Santos et al. (2006), que analisaram o sistema convencional o mesmo empregado neste trabalho em comparação ao teste de pesquisa molecular (PCR), avaliando um matadouro-frigorifico e três estabelecimentos não inspecionados, na mesma região demográfica, a técnica de PCR demonstrou ser mais viável, pois é mais segura, levando ao fácil isolamento o que apresentará menores resultados de falsos-positivos, além de ser mais rápida e mais sensível. Porém como resultados não houve diferença comparando as duas técnicas, mostrando que o método convencional ainda é eficaz e pode ser usado para a detecção de forma confiável deste microrganismo.

Para Fai et al. (2011), é necessário um maior rastreamento a nível nacional da presença da $L$. monocytogenes em alimentos que são direcionados ao consumidor, bem como normatizar padrões regulatórios para esse patógeno na legislação brasileira, garantindo a segurança de produtos cárneos e derivados, visto que, o consumo de matéria prima suína é expressivamente alto e cresce exponencialmente a cada ano. Desta forma, a presença de microrganismos patogênicos em alimentos, representa um perigo em potencial para a saúde pública, ressaltando ainda a necessidade de intensificar a fiscalização de produtos de origem 
animal quanto à inocuidade alimentar tanto para mercado interno como exportador.

\section{CONCLUSÃO}

Todas as amostras analisadas neste estudo não apresentaram contaminação por L. monocytogenes, demonstrando condições higiênico sanitárias satisfatórias e evidenciando boas práticas de manipulação sendo cumpridas pelo frigorífico, não oferecendo risco de contaminação aos consumidores, no entanto, se preconiza a continuidade da aplicação de forma efetiva de tais práticas para que se mantenha este padrão microbiológico e qualidade do produto.

\section{REFERÊNCIAS}

ABPA. Associação Brasileira de Proteína Animal. Relatório Anual de Atividades $2014 . \quad$ Disponível em: <http://abpabr.com.br/files/RelatorioAnual_UBABEF_2015_DIGITAL.pdf>. Acesso em: 01/04/2019.

ANVISA. AGÊNCIA NACIONAL DE VIGILÂNCIA SANITÁRIA. Resolução RDC no 12, de 2 de janeiro de 2001. Legislação, regulamento técnico sobre padrões microbiológicos para alimentos. 2001. Disponível em: <http://portal.anvisa.gov.br/documents/33880/2568070/RDC_12_2001.pdf/15ffddf63767-4527-bfac-740a0400829b >. Acesso em: 31/03/2019.

AMSON, G. V.; HARACEMIV, S. M. C.; MASSON, M. L. Levantamento de dados epidemiológicos relativos a ocorrências/ surtos de doenças transmitidas por alimentos (DTAs) no estado do Paraná-Brasil, no período de 1978 a 2000. Ciência e Agrotecnologia, Lavras, v. 30, n.6, p.1139-1145, 2006. Disponível em: <http://www.scielo.br/pdf/\%0D/cagro/v30n6/a16v30n6.pdf>. Acesso em 05/03/2019.

BRASIL. Ministério da Saúde. Secretaria de Vigilância em Saúde. Departamento de Vigilância das Doenças Transmissíveis. Coordenação Geral de Doenças Transmissíveis. Surtos de Doenças Transmitidas por Alimentos no Brasil. 2018. Disponível em: <http://portalarquivos2.saude.gov.br/images/pdf/2018/janeiro/17/ApresentacaoSurtos-DTA-2018.pdf>. Acesso em: 04/03/2019.

BRASIL. Ministério da Agricultura, Pecuária e Abastecimento. Instrução Normativa no 9, de 8 de abril de 2009. Disponível em: <http://www.agricultura.gov.br/assuntos/inspecao/produtos-animal/controle-depatogenos/arquivos-controle-de-patogenos/in_09-_de_8_de_abril_de_2009>. Acesso em: 11/01/2019.

CASANOVA. F. M.; SAMULAR. R. L.; MONTANHINI. M. T. M.; BITTENCOURT. J. V. M. Ocorrência de Listeria monocytogenes em abatedouro-frigorifico de suínos da região dos Campos Gerais - PR. Revista GEINTEC, São Cristóvão/SE, v. 4, n.5, p.1583 -1593, 2014. Disponível em: <http://www.revistageintec.net/index.php/revista/article/view/500/504>. Acesso em: 03/03/2019. DOI: 10.7198/S2237-0722201400050023.

CASELANI. K.; PRATA. L. F.; BIZARI. P. A.; PEREIRA. G. T.; MARCHI. P. G. F. et al. Ocorrência de Listeria spp. e de Listeria monocytogenes, em um matadourofrigorífico de bovinos do estado de São Paulo. Bioscience 
Journal. Uberlândia, v. 29, n. 4, p. 956-961, 2013. Disponível em: <http://www.seer.ufu.br/index.php/biosciencejournal/article/view/17284>. Acesso em 03/03/2019.

DA SILVA.; A. L.; ARAGON. C. C.; SANTANA. E. H. W.; DESTRO. M. T.; COSTA. M. R. et al. Listeria monocytogenes em Leite e Produtos Lácteos no Brasil: Uma Revisão. UNOPAR Cientifíca. Ciências biológicas e da saúde, v. 13, n.1, p. 59-67, 2011.

em: http://revista.pgsskroton.com.br/index.php/JHealthSci/article/view/1266/1214. DOI: http://dx.doi.org/10.17921/2447-8938.2011v13n1p\%25p.

FAI, A. E. C. FIGUEIREDO. E. A. T.; VERDIN. S. E. F.; PINHEIRO. N. M. S.; BRAGA. A. R. C. et al. Salmonella sp e Listeria monocytogenes em presunto suíno comercializado em supermercados de Fortaleza (CE, Brasil): fator de risco para a saúde pública. Ciência \& Saúde Coletiva, v.16, p. 657-662, 2011. Disponível em: <http://repositorio.unicamp.br/bitstream/REPOSIP/199294/1/pmed_21340341.pdf>. Acesso em: 01/03/2019.

ISO - International Standard Organization. ISO 11290-1 e ISO 11290-2. International Standard - Microbiology of food and animal feeding stuffs - horizontal method for the detection and enumeration of Listeria monocytogenes. Part 1: Detection method. 2004. Disponível em:<https://www.iso.org/standard/19268.html>. Acesso em: 01/04/2019.

MEDEIROS. M. G. A.; CARVALHO. L. R.; FRANCO. R. M. Percepção sobre a higiene dos manipuladores de alimentos e perfil microbiológico em restaurante universitário. Ciência \& Saúde Coletiva, v. 22, n. 2, p. 383-392, 2017. Disponível

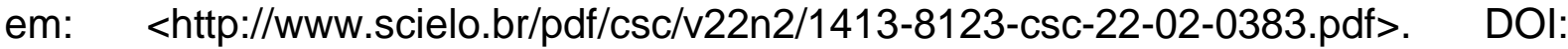
10.1590/1413-81232017222.17282015.

MELONI, D.; Piras. F.; Mureddu , A.; Fois, F.; Consolati. S.G. et al. Listeria monocytogenesin five Sardinian swineslaughterhouses: prevalence, serotype, and genotype characterization. Journal Food Protection, lowa, v.76, n.11, p.1863-1867, 2013. Disponível em: <https://www.ncbi.nlm.nih.gov/pubmed/24215688>. DOI:10.4315/0362-028X.JFP-12-505

NEVES, M. C. M. Levantamento de dados oriundos do DATASUS relativos à ocorrência/ surtos de intoxicação alimentar no Brasil de 2007-2014. Dissertação Universidade Federal de Paraíba, Pernambuco, 2015. Disponível em: <https://repositorio.ufpb.br/jspui/handle/123456789/1004>. Acesso em: 05/04/2019.

OMS - ORGANIZAÇÃO MUNDIAL DA SAÚDE. 2015. Disponível em: < http://www.who.int/campaigns/world-health-day/2015/event/en>. Acesso em: 22/03/2019.

PISSETTI, C.; WERLANG. G. O.; BIESUS. L. L.; KICH. J. D.; CARDOSO. M. R. I. Detecção de Salmonellaenterica e Listeriamonocytogenes em carcaças suínas na etapa de pré- resfriamento. Acta Scientiae Veterinatiae, Porto Alegre, v. 40, n. 4, p.1071, 2012. Disponível em: http://www.ufrgs.br/actavet/40-4/PUB\%201071.pdf. Acesso em 04/03/2019. 
RODRIGUES. C. S.; CORDEIRO DE SÁ. C. V. G.; MELO. C. B. An overview of Listeria monocytogenes contamination in ready to eat meat, dairy and fishery foods. Ciência Rural, Santa Maria, v.47: 02, e20160721, 2017. Disponível em: http://www.scielo.br/scielo.php?script=sci_arttext\&pid=S010384782017000200452\&n $\mathrm{g}=$ en\&tlng=en. DOI: http://dx.doi.org/10.1590/0103-8478cr20160721

SILVA. H. R.; GIANOGLOU. F. M.; CAMPOS. M. F.; GRACIANO. E. M. A.; TOLEDO. R. C. C. Listeriose: uma doença de origem alimentar pouco conhecida no Brasil. Revista Higiene Alimentar, v. 30, n. 262/263, 2016. Disponível em: <http://docs.bvsalud.org/biblioref/2017/02/827444/262-263-compressed-17-20.pdf>. Acesso em: 05/02/2019.

SANTOS, L. A. G. PINTO, P. S. de A.; MORAES, M. P.; VANETTI, M. C. D.; BEVILACQUA, P. D. et al. Pesquisa Molecular e Convencional de Listeriamonocytogenes para o controle de Qualidade da Carne Suína. Revista Ceres, Viçosa, v. 53 n. 308, p. 481-486, 2006. <Disponível em: https://www.redalyc.org/html/3052/305226674007/>. Acesso em: 22/03/2019.

SCALLAN, E.; HOEKSTRA, R. M.; ANGULO. F. J.; TAUXE. R. V.; WIDDOWSON. M. A. et al. Foodborne Illness Acquired in the United States - Major Pathogens. Emerging Infectious Diseases, Atlanta, v. 17, n. 1, p. 7-15, 2011. Disponível em: https://www.ncbi.nlm.nih.gov/pmc/articles/PMC3375761/.Doi: 10.3201/eid1701.P111 01. 